\title{
Lesão neoplásica em couro cabeludo: relato de caso
}

\author{
Injury neoplasm in scalp: case report
}

\section{Pedro Henrique Ferreira de Azevedo ${ }^{1}$, João Carlos de Souza Côrtes Júnior ${ }^{2}$, Humberto José Portella Garcia ${ }^{3}$, Maria Cristina Almeida de Souza, Edsneider Rocha Pires de Souza ${ }^{3}$, Paula Pitta de Resende Côrtes ${ }^{2}$}

\begin{abstract}
Azevedo PHF, Côrtes Júnior JCS, Garcia HJP, Souza MCA, Souza ERP, Côrtes PPR. Lesão neoplásica em couro cabeludo: relato de caso/Injury neoplasm in scalp: case report. Rev Med (São Paulo). 2017 out.-dez.;96(4):287-91.
\end{abstract}

RESUMO: Introdução: o carcinoma espinocelular consiste em uma neoplasia maligna dos queratinócitos epidérmicos supra basais, que frequentemente crescem em áreas fotoexpostas, sendo a exposição cumulativa à radiação ultravioleta o principal fator de risco. O carcinoma espinocelular contribui anualmente para os óbitos atribuídos ao câncer de pele não melanoma. É um tumor maligno das células espinhosas da epiderme, de evolução rápida, altamente invasivo e metastático. Objetivo: relatar um caso de carcinoma espinocelular, moderadamente diferenciado, na região de couro cabeludo com acometimento da calota craniana em indivíduo do gênero masculino, 68 anos, diabético, leucoderma, tabagista e etilista, que durante 10 anos exerceu atividades de ambulante na praia, sem utilização de qualquer proteção química ou mecânica contra o sol. Conclusão: ações de educação em saúde sobre proteção solar são essenciais para prevenção ao câncer de pele e devem ser incorporadas ao cotidiano da prática médica. $\mathrm{O}$ diagnóstico precoce está diretamente relacionado ao prognóstico da doença e à qualidade de vida do portador.

Palavras-chave: Carcinoma in situ; Neoplasia; Couro cabeludo/ patologia; Ceratose; Medicina clínica; Atenção primária à saúde; Carcinoma de células escamosas.

\begin{abstract}
Introduction: Squamous cell carcinoma consists in a malignant neoplasm of the basals epidermal keratinocytes, which often grow in sun-exposed areas and this cumulative exposure to ultraviolet radiation is its main risk factor. Each year, the squamous cell carcinoma contributes to thousands of deaths attributed to non-melanoma skin cancer. It is a malignant tumor of the prickle cells of the skin characterized by faster development, highly invasive and metastatic. Objective: To report a squamous cell carcinoma case, moderately differentiated, in the scalp area, with skullcap involvement in a male patient, 68 years old, diabetic, with light-skinned, smoker and alcohol consumer that during 10 years was a salesman on the beach without using any chemical or mechanical protection against the sun resulting inactinic keratosis lesions in sun-exposed areas. Conclusion: health education activities on sun protection are essential for prevention of skin cancer and should be incorporated into medical practice. Early diagnosis is directly related to the prognosis of the disease and the patient quality of life.
\end{abstract}

Keywords: Carcinoma in situ; Neoplasm; Scalp; Keratosis; Clinical medicine; Primary health care; Carcinoma, squamous cell.

1. Universidade Severino Sombra (USS), Vassouras, RJ, BR. Discente do Curso de Medicina. E-mail: pedro.ferreiraxd@gmail.com.

2. Universidade Severino Sombra (USS), Vassouras, RJ, BR. Docente do Curso de Medicina. Docente do Curso de Medicina da Universidade Estadual do Rio de Janeiro (UNIRIO).E-mail: joaocortes@yahoo.com.br, paulapitta@yahoo.com.br.

3. Universidade Severino Sombra (USS), Vassouras, RJ, BR. Docente do Curso de Medicina. Discente do Mestrado em Ciências Aplicadas em Saúde da Universidade Severino Sombra (USS). E-mail: cirurgiageral@uss.br, edsneidermed@yahoo.com.br.

4. Universidade Severino Sombra (USS), Vassouras, RJ, BR. Docente do Curso de Medicina. Docente do Mestrado em Ciências Aplicadas em Saúde da Universidade Severino Sombra (USS). E-mail: mcas.souza@uol.com.br.

Endereço para correspondência: Maria Cristina Almeida de Souza. Rua Aldo Cavalli, nº. 169. Centro - Vassouras, RJ. CEP: 27.700000.e mail:mcas.souza@uol.com.br 


\section{INTRODUÇÃO}

ânceres de pele não melanoma, especificamente
o carcinoma basocelular $(\mathrm{CBC})$ e o carcinoma espinocelular (CEC), constituem as neoplasias malignas de maior prevalência ${ }^{1}$. O CEC, também denominado carcinoma de células escamosas, é um tumor maligno das células espinhosas da epiderme, de evolução mais rápida e com maior poder invasivo e metastático que o $\mathrm{CBC}^{2}$. O CEC é a segunda forma mais comum de câncer cutâneo, representando 15 a 20\% do total destes tumores. Consiste em uma neoplasia maligna dos queratinócitos epidérmicos supra basais. Frequentemente se desenvolve em áreas expostas à radiação ultravioleta como orelhas, rosto, couro cabeludo e pescoço $0^{3,4}$. A exposição cumulativa à radiação ultravioleta representa o principal fator de risco ao surgimento desta lesão maligna ${ }^{5}$.

O CEC é duas vezes mais prevalente em homens que em mulheres, com predomínio em indivíduos a partir da quinta década de vida. Pode ocorrer em pessoas de qualquer cor, embora seja mais prevalente em caucasianos, que têm pele clara. A maioria das lesões é de baixo risco, com significativa diferenciação celular, originárias de ceratoses actínicas, consideradas como possíveis lesões precursoras. Há as formas de alto risco, com indiferenciação celular, que geralmente surgem a partir da Doença de Bowen (DB) e tornam-se invasivas, podendo causar metástase. A DB corresponde a um carcinoma espinocelular in situ, ou seja, de localização intra-epidérmica e crescimento lento. Caracteriza-se clinicamente por uma placa eritematosa circular bem definida, com 2 a 5 centímetros de diâmetro, com escamas aderentes e discreta infiltração. Quando de origem actínica, geralmente é solitária e as localizações mais comuns são a face, dorso das mãos, dorso dos dedos, braços e pernas. Em indivíduos com lesões múltiplas em áreas cobertas, no tronco, deve-se suspeitar de ingestão de arsênico como desencadeador do processo. Embora a DB seja potencialmente capaz de evoluir para um CEC invasivo, isto não é freqüente. A DB é geralmente tratada por excisão simples, mas há outras opções, tais como a eletrocoagulação, curetagem, radioterapia, quimioterapia tópica ou criocirurgia ${ }^{6}$.

Objetiva-se neste artigo descrever um caso de CEC, moderadamente diferenciado, com suas características clínicas e histológicas, na região de couro cabeludo. Destaca-se também a importância da atuação dos profissionais de saúde tanto na orientação à população acercada relevância de proteção solar como no diagnóstico precoce de lesões pré-neoplásicas e no compartilhamento de informações acerca dos fatores de risco ao surgimento do câncer.

\section{RELATO DE CASO}

Indivíduo do gênero masculino, 68 anos, diabético, de pele branca com sensibilidade ao sol, se enquadrando ao fototipo II, de acordo com a Classificação de Fitzpatrick ${ }^{1}$. Durante a consulta, na anamnese, relatou ser fumante com carga tabágica de 80 maços/ano e também etilista.

Durante 10 anos exerceu atividade laboral como vendedor ambulante na praia, sem utilização de qualquer proteção química ou mecânica contra a radiação solar. Informou também que, dois anos anteriores à consulta, houve um trauma de pequenas dimensões na região parietal póstero-superior do crânio, ocorrido acidentalmente enquanto exercia atividade laboral. Cerca de dez dias anteriores à consulta, percebeu uma lesão ulcerada em couro cabeludo, principal motivo que o levou a agendar uma consulta com o Médico de Família e Comunidade (MFC) da Estratégia da Saúde da Família (ESF) no município de Vassouras, Sul do Estado do Rio de Janeiro, onde reside e cuja cobertura populacional da ESF é de 100\%.

$\mathrm{Na}$ unidade de saúde, ao exame clínico, o MFC verificou pressão arterial sistêmica, sinais vitais e antropométricos normais. Foi solicitado hemograma completo e exame de urina, cujos resultados trazidos sete dias após, revelaram resultados normais. Constatouse então a necessidade de avaliação do caso por um especialista. Assim, por meio do sistema de Referência e Contrarreferência, encaminhou-se o indivíduo para a assistência em saúde na média complexidade, a fim de ser examinado pelo oncologista do Hospital Universitário de Vassouras (HUV), unidade de referência na atenção secundária à saúde.

Decorridos cerca de noventa dias, por meio do Agente Comunitário de Saúde, o MFC foi informado que o paciente não havia comparecido à consulta no HUV e a lesão havia evoluído, apresentando significativa área ulcerada, secreção purulenta, tecido necrótico, bordas irregulares e friáveis, com acometimento da calota craniana (Figura1).

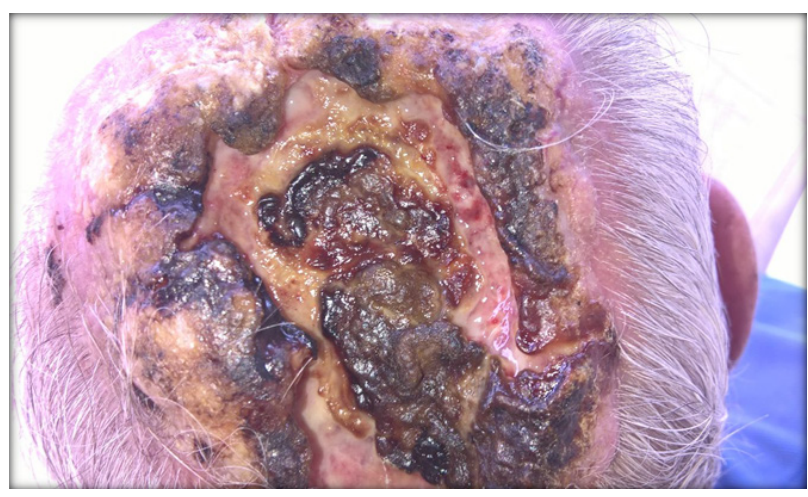

Figura 1. Lesão em estágio avançado após 3 meses de evolução 
No momento da internação, uma semana após, o paciente apresentava-se com estado de saúde satisfatório, lúcido, orientado no tempo e espaço, com histórico negativo de outros sintomas associados à doença atual. A equipe médica hospitalar observou ceratose actínica em membros superiores, além de pele xerodérmica (Figura 2).

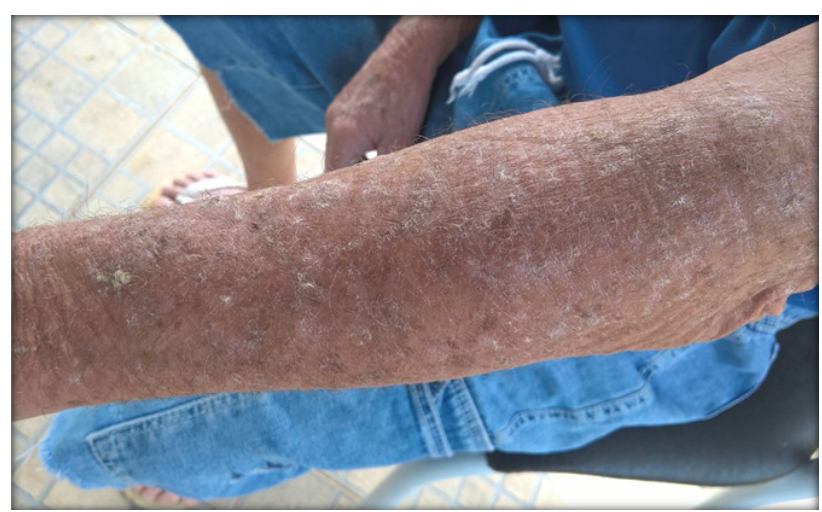

Figura 2. Presença de ceratose actínica em membro superior e pele xerodérmica

$\mathrm{Na}$ etapa seguinte, executou-se o desbridamento cirúrgico da área de necrose da lesão no couro cabeludo, com tratamento da infecção associada e realizou-se também uma biópsia. Não foram observadas linfonodomegalias em região cervical (Figura 3).

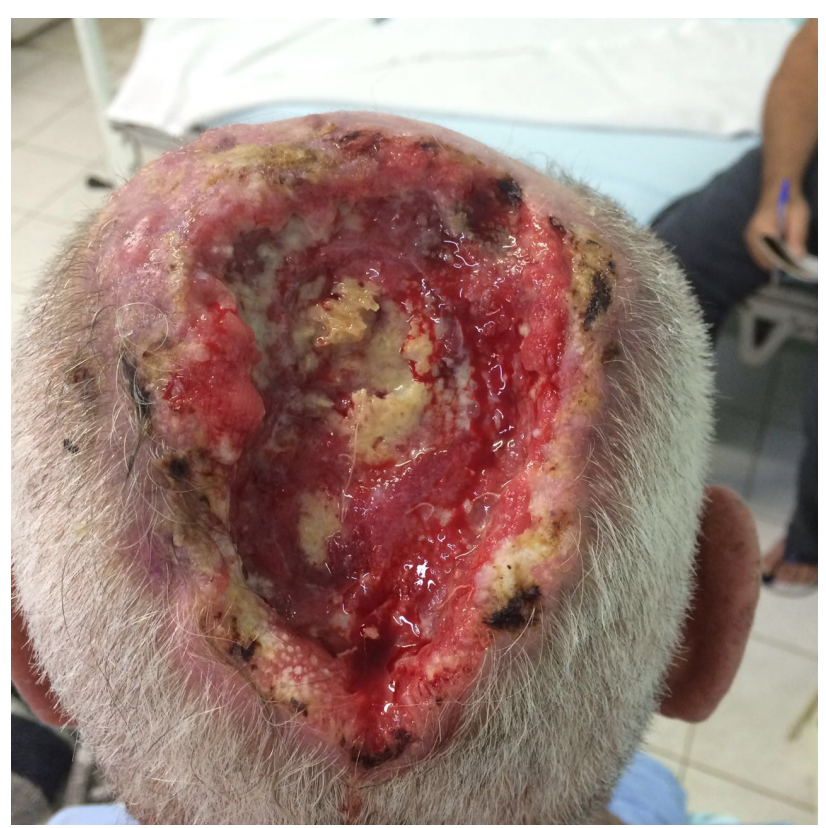

Figura 3. Desbridamento cirúrgico da área de necrose

O exame histopatológico da lesão diagnosticou CEC, moderadamente diferenciado, ulcerado, apresentando áreas com células claras, outras de aspecto acantolítico, ceratinização e necrose infiltrando em toda extensão dos segmentos, com presença de infiltração perineural.

O paciente manteve quadro clínico estável, sem evolução. A partir do décimo dia da internação, constatouse melhora da lesão, com redução da área necrótica e aumento do tecido de granulação. A imagem da tomografia computadorizada de crânio demonstrou formação sólida ulcerada no tecido subcutâneo na porção parietal pósterosuperior do crânio e destruição da calota craniana na região adjacente (Figura 4).

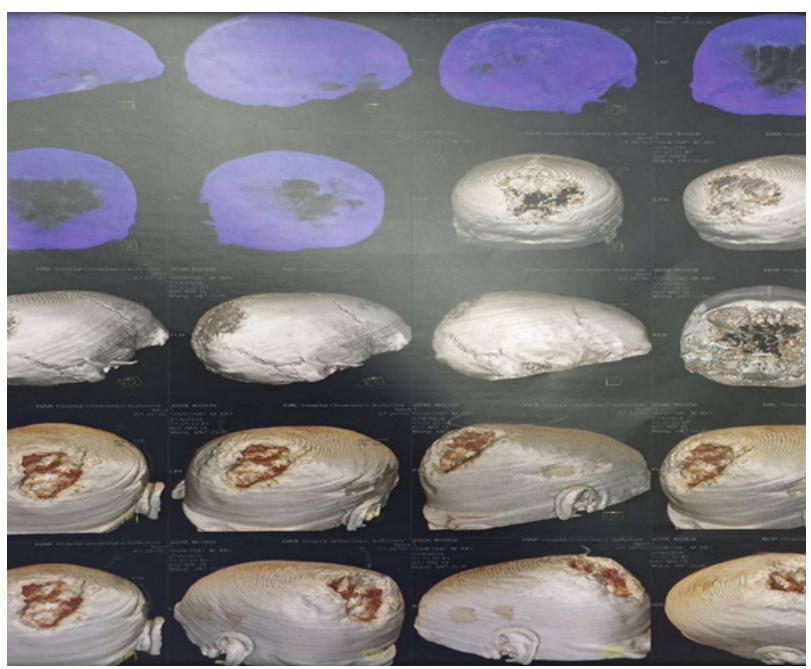

Figura 4. Tomografia computadorizada do crânio

Iniciou-se tratamento com radioterapia local devido à extensão da doença e a sua localização, fatos que contraindicaram a ressecção total. Foi programada a radioterapia em regime ambulatorial.

O paciente encontra-se em sua residência, sob acompanhamento da equipe multidisciplinar da unidade ESF, com a qual possui vínculo. No momento, o estado geral é satisfatório.

\section{DISCUSSÃO}

O câncer de pele configura-se como a neoplasia mais freqüente entre os cânceres. Apresenta-se basicamente sob duas formas, o melanoma e o não melanoma. Entre os cânceres de pele do tipo não melanoma, o CBC e o CEC são os mais frequentes, sendo o primeiro mais prevalente. Em geral, o CEC está associado exposição solar contínua, enquanto o CBC parece mais associado a uma exposição intermitente decorrente de altas doses de radiação solar ${ }^{5}$.

O CEC é um tumor maligno derivado da proliferação dos queratinócitos epidérmicos suprabasais. É responsável por $15-25 \%$ de todos os cânceres de pele não melanoma. A lesão neoplásica pode ser restrita à epiderme (CEC in situ) ou pode estender-se para além da membrana basal, alcançando a derme ou tecidos mais profundos (CEC invasor) ${ }^{6}$.

No caso relatado, o surgimento do CEC esteve 
relacionado a diversos fatores de risco, pois além da exposição solar contínua, havia histórico de etilismo e tabagismo. O principal fator predisponente identificado neste caso, e também descrito na literatura, foi a exposição cumulativa de raios ultravioleta, mais comum em áreas fotoexpostas, como orelhas, rosto, couro cabeludo, pescoço, dorso da mão e lábios. Há prevalência deste tipo de tumor em pessoas do gênero masculino, em geral, a partir da quinta década de vida. Entretanto, há relatos de CEC cada vez mais freqüente em indivíduos jovens, possivelmente pela exposição precoce ao sol da pele sem proteção solar. Destacam-se relatos de casos em pessoas de pele, cabelos e olhos claros (fototipo I e II de Fitzpatrick), que moram próximas à linha do Equador, onde é intensa a incidência solar. As pessoas que fumam estão mais propensas a desenvolver CEC, especialmentenas proximidades dos lábios. Outros fatores predisponentes para o desenvolvimento dessa neoplasia são a exposição às cabines de bronzeamento, à radioterapia com quadro de radiodermite crônica, pós queimadura com ulceração crônica, agentes químicos, arsenicismo, genodermatoses, infecção por HPV, imunossupressão e transplantados ${ }^{6}$.

As lesões precursoras clinicamente associadas ao CEC são ceratoses actínicas (CA), também denominadas de ceratose senil ou solar, e a DB (CEC in situ $)^{7,8}$. As CA se caracterizam como um problema comum na população e se apresentam como uma das lesões cutâneas mais tratadas pelos dermatologistas. A presença de CA no paciente do caso relatado também foi considerada um potencial precursor para o câncer não melanoma espinocelular ${ }^{9}, 10$.

Vale pormenorizar a discussão acerca da ceratose senil, considerada lesão potencialmente precursora das neoplasias. Historicamente considerada por vários autores como lesão pré maligna com grande potencial para se transformar em CEC, não há ainda hoje consenso por parte da comunidade científica sobre sua relação com as neoplasias ${ }^{4}$. As CA, assim como CEC in situ, são na verdade um único processo patológico, só que em diferentes fases do seu curso. O risco de progressão de CA para CEC varia de menos de 1 a $20 \%$, inferindo que nem toda ceratose senil transforma-se em CEC, podendo aquela persistir, regredir ou malignizar, tornando-se um CEC invasivo, dependendo de fatores individuais, como imunidade e genética.

As CA são marcadas pelas diversidades de aspectos de lesões que podem se apresentar, podendo ser únicas ou múltiplas, eritematosas, eritematodescamativas de superfície áspera, pardo-amarelada ou castanho-enegrecido, pápulo-ceratótica castanho escuro, tipo verrucoso, pápula com escama aderente e associação com elastose solar, lentigo solar e outras alterações próprias da pele fotolesadas são comumente observadas. As superfícies expostas aos raios ultravioleta (UV) são áreas preferenciais para o surgimento dessas lesões, como face, couro cabeludo, orelhas, pescoço, dorso das mãos e antebraços. Deve-se atentar para achados como dor, espessamento e ulceração, pois são indícios de transformação de $\mathrm{CA}$ para $\mathrm{CEC}^{6}$.

Outra lesão precursora que merece destaque é a $\mathrm{DB}$, cujo diagnóstico precoce evita a progressão para um possível carcicoma invasor. Clinicamente se apresenta como lesão eritemato-descamativa com superfície crostosa de limites precisos, devendo-se fazer diagnóstico diferencial com eczemas, doença de Paget e carcinoma basocelular. No exame dermatológico do paciente deste caso não foi evidenciada DB.

O prognóstico deste caso ainda é duvidoso, pois não foi constatado acometimento de linfonodo regional por invasão tumoral, de acordo com exame físico e com a tomografia de crânio. Tumores que se apresentam maiores que 2 centímetros, indiferenciados, com espessura de invasão maior que $4 \mathrm{~mm}$, nível IV na classificação de Clark ou que invadem tecido subcutâneo, são considerados de alto risco para metástase e recidiva, se apresentar um dos aspectos $^{3}$.

Visando a redução da mortalidade e da incapacidade causadas pelo câncer e a possibilidade de diminuir a incidência de alguns tipos de câncer, contribuir para a melhoria da qualidade de vida dos usuários com câncer, a Portaria 874, de 16 de maio de $2013^{11}$, instituiu a Política Nacional para a Prevenção e Controle do Câncer na Rede de Atenção à Saúde das pessoas com Doenças Crônicas no âmbito do Sistema Único de Saúde (SUS). Em seu artigo 26, define que os profissionais da atenção básica - entre os quais estão os que atuam na ESF - deverão realizar ações de promoção da saúde com foco nos fatores de risco ao câncer, desenvolver ações voltadas aos usuários de tabaco e avaliar a vulnerabilidade das pessoas com câncer.

Cabe destacar que as ações de educação em saúde, com ações de estímulo à proteção individual contra a luz solar, são altamente eficazes na prevenção primária do câncer de pele, além de serem de baixo custo. Estas medidas podem ser incorporadas ao processo de trabalho das equipes da ESF. Campanhas de prevenção e atividades de rastreamento têm se mostrado eficientes para diagnóstico precoce, pois contribuem com o tratamento, para a diminuição da morbidade e o aumento de sobrevida do paciente.

\section{CONCLUSÃO}

O relato apresentado destaca a relevância do diagnóstico precoce do CEC através de seu rastreamento e detecção. Enfatiza-se a necessidade de sua prevenção com ações de educação em saúde direcionadas à população, com estímulo a proteção individual e atuação sobre elementos modificadores da doença. Sendo assim, fatores de riscos, bem como lesões precursoras do CEC, devem ser identificados, principalmente na população idosa e nos indivíduos imunossuprimidos, por advirem sobre essas a maior morbimortalidade. Importante, portanto, que os profissionais da ESF sejam capacitados a diagnosticar, de 
maneira rápida e eficaz, as lesões pré-malignas, a fim de encaminhar oportunamente ao especialista, aumentando a probabilidade de cura e diminuindo os custos com tratamento e gastos da saúde pública, além de contribuir para a qualidade de vida do paciente e de sua família.

\section{REFERÊNCIAS}

1. Woff k, Goldsmith LAG, Katz SI, Gilchrest BA, Paller AS, Leffell DJ. Carcinoma epidermóide. In: Wolff K, et al. Fitzpatrick - tratado de dermatologia. 7a ed. Rio de Janeiro: Revinter; 2011. p.1035-8.

2. Brasil. Ministério de Saúde. Instituto Nacional de Câncer José Alencar Gomes da Silva. Estimativa 2016: incidência de câncer no Brasil. Rio de Janeiro: INCA; 2015. Disponível em: http://www.inca.gov.br/estimativa/2016/estimativa-2016-v11. pdf.

3. Enokihara MY, Simões MM, Enokihara S. Carcionoma basocelular e Carcionoma espinocelular. In: Lupi O, Belo J, Cunha PR. Rotinas de diagnóstico e tratamento da Sociedade Brasileira de Dermatologia. São Paulo: Ac Farmacêutica; 2010. p.29-35.

4. Soyer HP, Rigel DS, Wurm EMT. Queratose actínica, Carcinoma basocelular e carcinoma espinocelular. In: Bolognia JL, Jorizzo JL, Schaffer JV. Dermatologia. 3a ed. Rio de Janeiro: Elsevier; 2015. p.5156-215.

5. Margotto HPS, Meireles RS, Neugebauer MGFP, Abrahão GF, Rauber JL. Fotoexposição e fatores de risco para câncer de pele: avaliação de hábitos e conhecimentos da população participante da campanha de prevenção ao câncer de pele em Morro Redondo/RS. Rev AMRIGS. 2016;60(1):32-7. doi: http://dx.doi.org/10.1590/S0365-05962010000200007.

6. Brito AC. Tumores e proliferações epiteliais. In: Ramos e
Participação dos autores: todos os autores participaram igualmente em todas as etapas da elaboração e redação do artigo. Conflito de interesse: Os autores declaram não haver conflito de interesses.

Fonte de Financiamento: não há.
Silva M, Castro MCR. Fundamentos de dermatologia. 2a ed. Rio de Janeiro: Atheneu; 2010. p.1542-5.

7. Cohen JL. Actinic keratosis treatment as a key component of preventive strategies for non melanoma skin cancer. J Clin Aesthet Dermatol. 2010;3(6):39-44. Disponível em: http:// www.ncbi.nlm.nih.gov/pubmed/20725550.

8. Lebwohl M. Actinic keratosis: epidemiology and progression to squamous cell carcinoma. Br J Dermatol. 2003; 149(Suppl)66:31-3. Disponível em: https://www.ncbi.nlm. nih.gov/pubmed/14616345.

9. Salasche SJ. Epidemiology of actinic keratoses and squamous cell carcinoma. J Am Acad Dermatol. 2000;42:4-7. doi: http:// dx.doi.org/10.1067/mjd.2000.103342.

10. Criscione VD, Weinstock MA, Naylor MF, Luque C, Eide MJ, Bingham SF. Actinic keratoses: natural history and risk of malignant transformation in the Veterans Affairs Topical Tretinoin Chemoprevention Trial. Cancer. 2009; 1;115(11):2523-30. doi: 10.1002/cncr.24284.

11. Brasil. Ministério da Saúde. Portaria no. 874, de 16 de Maio de 2013. Institui a Política Nacional para a Prevenção e Controle do Câncer na Rede de Atenção à Saúde das Pessoas com Doenças Crônicas no âmbito do Sistema Único de Saúde (SUS). Disponível em: http://bvsms.saude.gov.br/bvs/ saudelegis/gm/2013/prt0874_16 05 2013.html 